TREATMENT OF FAT ATROPHY AT INJECTION SITES IN DIABETIC CHILDREN.

Hans K. Akerblom and Matti K. Kiviluoto. The Children s Hospital, University of Helsinki, Helsinki,finland.

The effect of local treatment with insulin of subcutaneous fat atrophy at the injection sites was studied in five diabetic children, aged 7 to 15 years. Their diabetes had been treated with lente insulin in four cases and with a biphasic insulin preparation in one case. The atrophic areas were 10cated in the thighs and buttocks.

The local treatment consisted of injecting s.c. four units of regular (Actrapid insulin per day circularly around the atrophic area, 2-3 millimetres from the border on the unaffected side. The effect of the local treatment was checked by measuring repeatedly the diameters and fat fold thicknesses of the atrophic areas and by comparing the results to corresponding parameters of untreated atrophic areas in the same patients. Local administration of a small amount of regular insulin resulted in a diminution of the atrophic sites within one month in all five patients, and complete disappearance of the subcutaneous fat atrophy occurred within three months in four patients.

\section{NEONATAL TOPICS}

CONGENITAL STERNOMASTOID TORTICOLLIS: AN INTRAUTERINE POSTURAL DEFORMITY. P.M. Dunn (Bristol).

During a study of 6756 consecutive newborn infants, congenital sternomastoid torticollis (CST) was observed in association with plagiocephaly $(P<<0.001)$, facial deformities $(P<0.05)$, ipselateral mandibular asymmetry $(P<<0.001)$, postura scoliosis $(P<<0.001)$ and talipes $(P<0.001)$. A similar pattern of maternal pregnancy characteristics (eg.primiparity, oligohydramnios, breech presentation) was observed as is encountered in association with other congenital postural deformities. Clinical and pathological data collected over a 14 year period suggests that CST is due to prenatal fibrosis and shortening of the muscle. This may be caused by ischaemia secondary to venous occlusion due to persistant lateral flexion and rotation of the neck before birth. Trauma to the shortened muscle during delivery may be responsible for secondary damage in some cases.

STUDIES ON NEONATAL SCALP HAIR REFLECTING INTRAUTERINE NUTRITION.

David Baum and Dorothy Harris.Department of Paediatrics, John Radcliffe Hospital, oxford.

Three groups of infants were studied:

1. Term infants, normal weight for dates

2. Infants born very early, normal weight for dates

3. Infants born small for dates.

Hair samples were studied morphologically and the diameters measured precisely using a scanning electron microscope.

Normal weight for dates term infants had hairs which tapered towards the tip.

Infants born very early had narrower hairs: these could be superimposed upon the distal segments of the term infants' hairs.

Small for dates infants had hairs which were of narrower diameter for gestational age than the equivalent hair segments from normally grown infants.

Amino acid analysis of the hairs showed no differences in pattern among the three groups. These results will be discussed.
THE GROWTH OF CHILDREN BORN WITH LOW BIRTH WEIGHT AFTER 10 YEARS. K. Polácek and $A$. Syrovatka

Main parameters of growth (weight, height, head circumference) were estimated in i 23 preterm children born with the appropriate birth weight, 60 small-for-dates (SFD) children born in term, 42 SFD children born before term and 120 full term healthy children (control group) when they reached the age of 10 years. Mean values of growth parameters were lower in all groups of children with LBW; the difference was significant only in both groups of SFD children, the worst results being in preterm SFD children. The low mean values were due to the larger proportion of children with subnormal parameters of growth in all groups of LBW children. in SFD children also due to the higher incidence of more severe cases. It seems that the long-lasting alteration of growth is more prominent in children with the prenatal malnutrition than in those with the shortening of gestation. The incidence of growth retarded children was less in girls, probably due to the influence of the beginning puberty.

VERY LOW BIRTH WEIGHT AND LATER INTELLIGENCE.

Jessie Francis-Williams and Pamela A.Davies.

Intelligence testing, using the Wechsler Intelligence Scale for Children and the Wechsler Preschool and Primary Scale of Intelligence, has been carried out on nearly 100 children who weighed $1500 \mathrm{G}$ and less at birth. They were born between 1961 and 1968 inclusive, and were cared for at Hammersmith Hospital,London. The youngest child had reached 4 years at the time of testing.

Significant differences in food intake and body temperature in the neonatal period existed between the years 1961-64 and 1965-68. The influence, if any, of these factors and of other perinatal events on subsequent events is discussed. The performance of children of low birth weight for gestational age is contrasted with that of children who were appropriately grown at the time of birth.
THE EFFECT OF MATERNAL EXERCISE ON FETAL HEART RATE AND SOME BIOCHEMICAL TEST REFLECTING FETOPLACENTAL FUNCTION. L. -E. Bratteby, B. Lindberg \&B.A. Nilsson. Department of Paediatrics, Clinical Physiology and Obstetrics and Gynecology, University Hospital, Uppsala, Sweden.

Six healthy women in the last trimester of pregnancy were exposed to long term, strenous exercise on an ergometer bicycle. Before,during and after the exercise their heart rate, blood pressure, and respiration rate were continuously recorded and repeated samples of venous blood obtained. Fetal heart rate was monitored using an ultrasound instrument. In most cases a significant increase in fetal heart rate was recorded during maternal exercise but different patterns of change in fetal heart rate were observed. Also the levels of progesterone, estradiol, estriol and chorionic somatotropin in maternal piasma varied during maternal exercise.

The different patterns of changes in fetal heart rate and in the biochemical tests will be discussed. 